\title{
Obesity Kills: Can Genetics Help in the Targeting of Obesity Prevention?
}

\section{Terho Lehtimäki*}

Department of Clinical Chemistry Fimlab Laboratories and University of Tampere School of Medicine, Tampere, Finland

\section{Facts:}

- Obesity is becoming a worldwide epidemic and is a major public-health-threatening problem in most countries in the world. A recent paper in The Lancet [1] involving 19.2 million participants broke the news by forecasting that, if the current trends of weight gain continue, by 2025 , the global obesity (BMI $>30)$ prevalence will reach $18 \%$ among men and surpass $21 \%$ among women (39\% for all); severe obesity will exceed $6 \%$ among men and $9 \%$ among women (BMI $>35,15 \%$ for all).

- Obesity means an excess accumulation of body fat tissue and is caused by a combination of excessive food intake, a lack of physical activity, and genetic susceptibility.

- Severe and morbid obesity are associated with highly elevated risks of adverse health outcomes, i.e., metabolic diseases (type 2 diabetes), higher morbidity and mortality for a variety of diseases as well as higher overall mortality. It has been estimated that overweight decreases an individual's life expectancy by eight years.

- The number of gene loci associated significantly $\left(\mathrm{p}<5 \times 10^{-8}\right)$ in genome-wide analyses (GWA) with adult weigh traits, i.e., body mass index, waist-to-hip ratio and body fat $\%$ - is currently over 110 [2-4] and 60 loci were recently found to associate with birth weight [5], which is a predictor of adulthood obesity. The identified new loci were enriched for genes expressed in adipose tissue and for putative regulatory elements in adipocytes. Pathway analyses provide strong support for a role of the central nervous system, the neurosecretory system, in susceptibility to obesity and implicate new genes and pathways, including those related to synaptic function, glutamate signalling, insulin secretion/action, energy metabolism, lipid biology and adipogenesis. The ongoing genome sequencing efforts will soon widen the genetic map of weigh-trait and obesity-related gene loci. This provides stronger genetic instruments for the prediction of obesity and allows the scientists to construct obesity risk calculators considering lifestyle, clinical measures, family history, ethnicity and individual genome variation information in the estimation of the life-time risk of obesity.

- At the moment, we do not have sufficient means to stop this "fat epidemic" or prevent its consequences, but we also know that existing morbid obesity and its consequences are extremely difficult to treat.

In recent work by Dr. Horikoshi and members of the Early Growth Genetics (EGG) Consortium in Nature [5], the researchers analysed genetic differences throughout the genomes of nearly 154,000 people from across the world. By relating the genetic profiles of these individuals to information on birth weight, the researchers were able to identify 60 regions of the genome that were driving the differences in birth weight. They then analysed data from previous GWA studies on conditions including body weight, body mass index, obesity in adulthood, childhood obesity, blood pressure, diabetes and heart disease, and found that many of the same genomic regions were highly significantly associated with all of these traits later in life. The research concluded that a substantial proportion, at least $15 \%$, of the variation in birth weight is down to genetic differences between babies. This is seven to eight times more variation than can be explained by environmental factors already known to influence birth weight, such as the mother's smoking during pregnancy or her body mass index before pregnancy. The important message from this study and the "foetal origins of adult disease hypothesis" by David Barker is that the prevention of obesity, diabetes and cardiovascular diseases should begin antenatally in utero in the period of early embryo development by altering the maternal nutritional or non-nutritional status and thus epigenetically regulating the functions of these birth-weight- and adultdisease-associated genes. It has been known for some time that babies whose birth weight is well below or well above the average have a markedly increased risk of obesity and diabetes many decades later. Those born large for their gestational age had a higher body mass index throughout childhood, adolescence and young adulthood $(26.4$ $\mathrm{kg} / \mathrm{m}^{2}$ [SD 4.9]), than those with a normal birth weight $\left(25.1 \mathrm{~kg} / \mathrm{m}^{2}\right.$ [SD 4.6]; $\mathrm{P}=0.002$ ), and they had a 2 -fold greater risk of obesity [6]. Weight at birth is influenced by many factors, including the baby's genes and those of its parents, as well as the nutrition made available and the environment provided by the mother. Thanks to these new results, we now have a much more detailed view of the ways in which these genetic and environmental elements interact to influence early growth and later disease. Using this new weight-associated genetic loci data [2-5], we can now form so-called genetic risk scores for polygenic birth weight and adult obesity traits for the identification of babies and children with a genetic risk of obesity in adulthood. This is important, since there is a high degree of continuity when it comes to overweight and obesity throughout the course of an individual's life, indicating that overweight and obesity in childhood tend to persist into adulthood [7]. Therefore, the obesity prevention should start in childhood and cover the critical growth period from childhood throughout adolescence into adulthood. Most of this overlap involves the baby's genetic profile, but the research team found that the mother's genes also played an important role in influencing her baby's birth weight, most likely through the ways in which they alter the baby's environment during pregnancy [5]. Therefore, it is important to include genetic profiling, i.e. the weight-related risk score of the mother in addition to that of the baby, in the prediction models when evaluating children's future risk of obesity in adulthood. Earlier genetic risk scores based on a significantly lower number of BMI-, weight- or obesity-related loci have been too weak, explaining only a

*Corresponding author: Terho Lehtimäki, Department of Clinical Chemistry Fimlab Laboratories and University of Tampere School of Medicine, Tampere, Finland, Tel: +358 (0)50 433 6285; E-mail: terho.lehtimaki@uta.fi

Received October 10, 2016; Accepted October 12, 2016; Published October 19 2016

Citation: Lehtimäki T (2016) Obesity Kills: Can Genetics Help in the Targeting of Obesity Prevention? J Clin Med Genomics 4: e101. doi: $10.4172 / 2472-128 \times .1000$ e101

Copyright: (c) 2016 Lehtimäki T. This is an open-access article distributed under the terms of the Creative Commons Attribution License, which permits unrestricted use, distribution, and reproduction in any medium, provided the original author and source are credited. 
Citation: Lehtimäki T (2016) Obesity Kills: Can Genetics Help in the Targeting of Obesity Prevention? J Clin Med Genomics 4: e101. doi: 10.4172/2472-128X.1000e101

Page 2 of 2

very small portion of the genetic variance related to body weight or obesity risk. The fast extension of the genetic map of body weight is, for the first time, allowing the prediction of obesity over and beyond classical obesity risk factors. This will offer new possibilities to target prevention already in childhood among those with the greatest risk of future obesity in adulthood.

\section{References}

1. NCD Risk Factor Collaboration (NCD-RisC) (2016) Trends in adult body-mass index in 200 countries from 1975 to 2014 : A pooled analysis of 1698 populationbased measurement studies with $19 \cdot 2$ million participants. Lancet 387: 1377 -

2. Locke AE, Kahali B, Berndt SI, Justice AE, Pers TH, et al. (2015) Genetic studies of body mass index yield new insights for obesity biology. Nature 518 : 197-206.
3. Shungin D, Winkler TW, Croteau-Chonka DC, Ferreira T, Locke AE, et al. (2015) New genetic loci link adipose and insulin biology to body fat distribution. Nature 518: 187-196.

4. Gusev A, Ko A, Shi H, Bhatia G, Chung W, et al. (2016) Integrative approaches for large-scale transcriptome-wide association studies. Nat Genet 48: 245-252.

5. Horikoshi M, Beaumont RN, Day FR, Warrington NM, Kooijman MN, et al (2016) Genome-wide associations for birth weight and correlations with adult disease. Nature.

6. Skilton MR, Siitonen N, Würtz P, Viikari JS, Juonala M, et al. (2014) High birth weight is associated with obesity and increased carotid wall thickness in young adults: The cardiovascular risk in young Finns study. Arterioscler Thromb Vasc Biol 34: 1064-1068.

7. Juonala M, Juhola J, Magnussen CG, Würtz P, Viikari JS, et al. (2011) Childhood environmental and genetic predictors of adulthood obesity: The cardiovascular risk in young Finns study. J Clin Endocrinol Metab 96: E1542-1549. 